\title{
Hierarchically imprinted polymer for peptide tag recognition based on an oriented surface epitope approach
}

Lidia N. Gómez-Arribas ${ }^{\dagger}$, María del Mar Darder ${ }^{\dagger}$, Nuria García ${ }^{\ddagger}$, Yoel Rodríguez $^{\S, \perp}$, Javier L. Urracat, ${ }^{\dagger, *}$ and María C. Moreno-Bondit,"

† Chemical Optosensors and Applied Photochemistry Group (GSOLFA), Department of Analytical Chemistry, Faculty of Chemistry, Complutense University of Madrid, 28040 Madrid, Spain

‡ Instituto de Ciencia y Tecnología de Polímeros (ICTP), CSIC, Calle Juan de la Cierva 3, 28006 Madrid, Spain

\& Department of Natural Sciences, Hostos Community College of CUNY, 500 Grand Concourse, Bronx, New York, NY 10451, USA

$\perp$ Department of Pharmacological Sciences, Icahn School of Medicine at Mount Sinai, 1425 Madison Avenue, New York, NY 10029, USA

*Corresponding authors: jurracar@ucm.es, mcmbondi@ucm.es 


\section{TABLE OF CONTENTS}

List of acronyms

Introduction

Experimental section

S1. Reagents and chemicals

S2. Techniques for particle characterization

S3. HPLC methods

S4. Hierarchically imprinted polymer synthesis

S5. Molecularly imprinted solid phase extraction (MISPE) for cross-reactivity studies

S6. Methods and models of computational study of DYKDC peptide/EAMA complex, and DYKD and DYKDDDDK peptides

Results and discussion section

S7. Equations

S8. Characterization of derivatized silica beads

S9. Hierarchically imprinted MIP-AZA polymers

S10. Computational study of DYKDC peptide/EAMA complex, and DYKD and DYKDDDDK peptides 


\section{LIST OF ACRONYMS}

AEAPMS: (3-(2-aminoethylamino) propyldimethoxymethylsilane.

AETAZS: $N$-(2-aminoethyl)-2,2,4-trimethyl-1-aza-2-silacyclopentane.

PTSA: $p$-toluensulfonic acid.

DMAP: 4- dimethylaminopyridine.

EAMA: $\mathrm{N}$-(2-aminoethyl)methacrylamide hydrochloride.

EDMA: ethyleneglycol dimethacrylate.

ABDV: 2,2 -azobis(2,4-dimethylvaleronitrile).

Si-DMPTSA1, Si-DMPTSA2, Si-DMPTSA3, Si-DMPTSA4: silica particles functionalized with difunctional silane AEAPMS at $110^{\circ} \mathrm{C}$ using PTSA as catalyst.

Si-DMRT: silica particles functionalized with difunctional silane AEAPMS at room temperature in absence of catalyst.

Si-DM-IAc: iodoacetylated Si-DMPTSA1 particles.

Si-DM-Pept: Si-DM-IAc particles derivatized with DYKDC peptide.

MIP-DM: molecularly imprinted polymer synthesized using Si-DM-Pept as scaffold.

NIP-DM: molecularly non imprinted polymer synthesized using Si-DM-IAc as scaffold.

Si-AZA1, Si-AZA2, Si-AZA3: silica particles functionalized with monofunctional silane AETAZS.

Si-AZA-IAc: iodoacetylated Si-AZA1 silica particles.

Si-AZA-Pept: Si-AZA-IAc particles derivatized with DYKDC peptide.

MIP-AZA: molecularly imprinted polymer synthesized using Si-AZA-Pept particles as scaffold.

NIP-AZA: molecularly non imprinted polymer synthesized using Si-AZA-IAc particles as scaffold.

MISPE: Molecularly Imprinted Solid Phase Extraction. 


\section{INTRODUCTION}

Table S1. Comparison between MIPs and antibodies for their application in analytical separations. ${ }^{1-4}$

\begin{tabular}{|c|c|c|}
\hline & MIPs & Antibodies \\
\hline Lifetime & Years & 6-12 months \\
\hline Storage & $\begin{array}{l}\text { From } 4{ }^{\circ} \mathrm{C} \text { to room } \\
\text { temperature }\end{array}$ & Freezer \\
\hline Reusability & Extended & Limited \\
\hline Solvent compatibility & $\begin{array}{c}\text { Compatible with most } \\
\text { organic and aqueous } \\
\text { solvents }\end{array}$ & $\begin{array}{l}\text { Compatible with aqueous- } \\
\text { based media }\end{array}$ \\
\hline Sterilization & UV, autoclaving & $\begin{array}{c}\text { Problematic, typically using } \\
\text { Y-irradiation }\end{array}$ \\
\hline Stability & $\begin{array}{l}\text { Robust, resistant to extreme } \\
\text { conditions }\end{array}$ & $\begin{array}{l}\text { Unstable in extreme } \\
\text { conditions, easy denaturation }\end{array}$ \\
\hline Selectivity & Medium-High & High \\
\hline Binding capacity & $\begin{array}{c}\text { Variable } \\
\left(\sim 1 \mathrm{mg} \mathrm{g}^{-1}\right)^{(\mathrm{b})}\end{array}$ & $\begin{array}{c}\text { Variable } \\
\left(\sim 0.6 \mathrm{mg} \mathrm{mL}^{-1}\right)^{(\mathrm{c})}\end{array}$ \\
\hline Price (a) & $0.25-5 \$ / \mathrm{mg}$ & $1-1000 \$ / \mathrm{mg}$ \\
\hline
\end{tabular}

(a) Poma, A.; Guerreiro, A.; Whitcombe, M. J.; Piletska, E. V.; Turner, A.P.F.; Piletsky, S.A. Solid-Phase Synthesis of Molecularly Imprinted Polymer Nanoparticles with a Reusable Template-"Plastic Antibodies". Adv. Funct. Mater. 2013, 23, 2821-2827.

(b) Binding capacity for FLAG peptide obtained in the present work (MIP-AZA polymer).

(c) Binding capacity for FLAG-BAP Fusion Protein (Sigma-Aldrich) in the anti-FLAG M2 Affinity Gel (Sigma Aldrich).

\section{EXPERIMENTAL SECTION}

\section{S1. Reagents and chemicals}

Hydrochloric acid (36.5-38\%), toluene (>99.9\%) and triethylamine (>99\%) were from Scharlau. Silica microspheres (SiliaSphereTM PC, 40-75 m diameter, 500Ả pore size, SiliCycle, www.silicycle.com). 3-(2-Aminoethylamino)propyldimethoxymethylsilane (AEAPMS, $\geq 95 \%$ ), p-toluenesulfonic acid (PTSA, 98.5\%), anhydrous toluene (99.8\%), acetonitrile $(\mathrm{AcN})$, methanol (MeOH, HPLC grade), ethylene glycol dimethacrylate (EDMA), 2-[4-(2-hydroxyethyl)-1-piperazinyl]ethanesulfonic acid (HEPES) and tetrabutylammonium hydrogensulfate (TBA) were from Sigma-Aldrich (St. Louis, MO, USA). Water was purified with a Millipore Direct-Q system (Bedford, MA, USA). N-(2aminoethyl)-2,2,4-trimethyl-1-aza-2-silacyclopentane (AETAZS, >95\%) was from Gelest. Absolute ethanol, dimethylsulfoxide and dimethylformamide (DMF, >98\%) were from VWR chemicals. lodoacetic anhydride and anhydrous dimethylformamide ( $>99.8 \%)$ were from Acros Organic. $\mathrm{N}$-(2-aminoethyl)methacrylamide hydrochloride (EAMA) was from Polysciences. 2,2 -azobis(2,4-dimethylvaleronitrile (ABDV) was from Wako Pure 
Chemicals (Neuss, Germany). 4-Dimethylaminopyridine (DMAP, >98\%) was from Fluorochem. Peptides DYKD and DYKDDDDK were from Peptide Sciences. Peptide DYKDC was from China Peptides. Ammonium hydrogen difluoride was from Fischer Scientific. Peptides GRGDNP and YPYDVPDYA were from GenScript. Trifluoroacetic acid (TFA) was purchased to Alfa Aesar.

\section{S2. Techniques for particle characterization}

Derivatized silica particles and imprinted polymers were subjected to several characterization techniques. Functionalization degree of silica particles was estimated from elemental microanalysis obtained by using a CHNS-932 microanalyzer in Centre for Elemental Microanalysis (UCM, Madrid). Scope of validation for each element was \%C (0.53-82.42); \%H (2.75-6.71), \%N (0.45-20.13) and \%S (0.57-26.69). Established uncertainty for each element is $\pm 0.35 \%$ for carbon content, $\pm 0.30 \%$ for hydrogen and nitrogen content and $\pm 0.35 \%$ for sulfur content.

Specific surface area and specific pore volume of functionalized silica particles were evaluated from $\mathrm{N}_{2}$ adsorption/desorption analysis recorded at $-196 \stackrel{\circ}{\circ}$ on a Micromeritics ASAP 2020 Surface Area and Porosity Analyzer. Before measurements, samples were outgassed at $50 \stackrel{\circ}{ } \mathrm{C}$ for $2 \mathrm{~h}$ and $30{ }^{\circ} \mathrm{C}$ for $8 \mathrm{~h}$ under high vacuum $\left(10^{-3} \mathrm{Torr}\right)$. The specific surface areas $\left(\mathrm{S}_{\mathrm{A}}\right)$ were evaluated using the BET method and the specific pore volumes $\left(V_{p}\right)$ were determined using the Barret-Joyner-Halenda method (BJH). Particle morphology and size distribution were determined by Scanning Electron Microscopy (SEM) using JEOL JSM 6335F electron microscope in the Spanish National Centre for Electron Microscopy (UCM, Madrid) and further processed by ImageJ software.

The NMR spectra of the silica were performed in a Bruker Avance 400 spectrometer (Bruker Analytik GmbH Karlsrube, Germany) equipped with a Bruker Ultrashield 9.4 T, $8.9 \mathrm{~cm}$ vertical-bore superconducting magnet. ${ }^{29} \mathrm{Si} \mathrm{CP} / \mathrm{MAS}$ NMR spectra were acquired at ambient temperature by using a standard Bruker broad-band MAS probe. Representative samples were ground and packed in $4 \mathrm{~mm}$ zirconia rotors, sealed with Kel-F caps and spun at $5 \mathrm{kHz}$. The 90-pulse width was 3.5-4.5 ms and, in all cases, highpower proton decoupling was used. All free-induction decays were subjected to standard Fourier transformation and phasing. The chemical shifts were externally referenced to TMS. The spectra were obtained with $4 \mathrm{~ms}$ CP contact time, $4 \mathrm{~s}$ recycle delay, 16000 averages, and $80 \mathrm{~Hz}$ line broadening.

\section{S3. HPLC methods}

Chromatographic analyses were done on an Agilent 1200 series (Palo Alto, CA, USA) equipped with a binary pump, online degasser, high-performance autosampler, 
column thermostat and 1260 Infinity diode array detector (DAD) system. Recoveries (\%) were calculated from external calibration peak area measurements. All peptides were quantified at $\lambda=220 \mathrm{~nm}$.

\subsection{DYKD and FLAG peptides}

Chromatographic separation was done with an ACE Excel $2 \mathrm{C}_{18}$-PFP analytical column $(100 \mathrm{~mm} \times 2.1 \mathrm{~mm}, 2 \mu \mathrm{m})$ from ACE at $30^{\circ} \mathrm{C}$. The mobile phase was a mixture of solvent $\mathrm{A}$ (water/trifluoroacetic acid, TFA $0.1 \%(\mathrm{v} / \mathrm{v})$ ) and solvent $\mathrm{B}$ (acetonitrile, $\mathrm{AcN}$ ), and used according to the following gradient programme: $97 \% \mathrm{~A}$ (0-10 $\mathrm{min}$ ), $97-20 \% \mathrm{~A}$ (10-10.1 min), 20\% A (10.1-11-1 min), 20-97\% A (11.1-11.2 min) and 97\% A (11.2-25 min). The flow rate was $0.4 \mathrm{~mL} \mathrm{~min}^{-1}$ and the injected volume $5 \mu \mathrm{L}$.

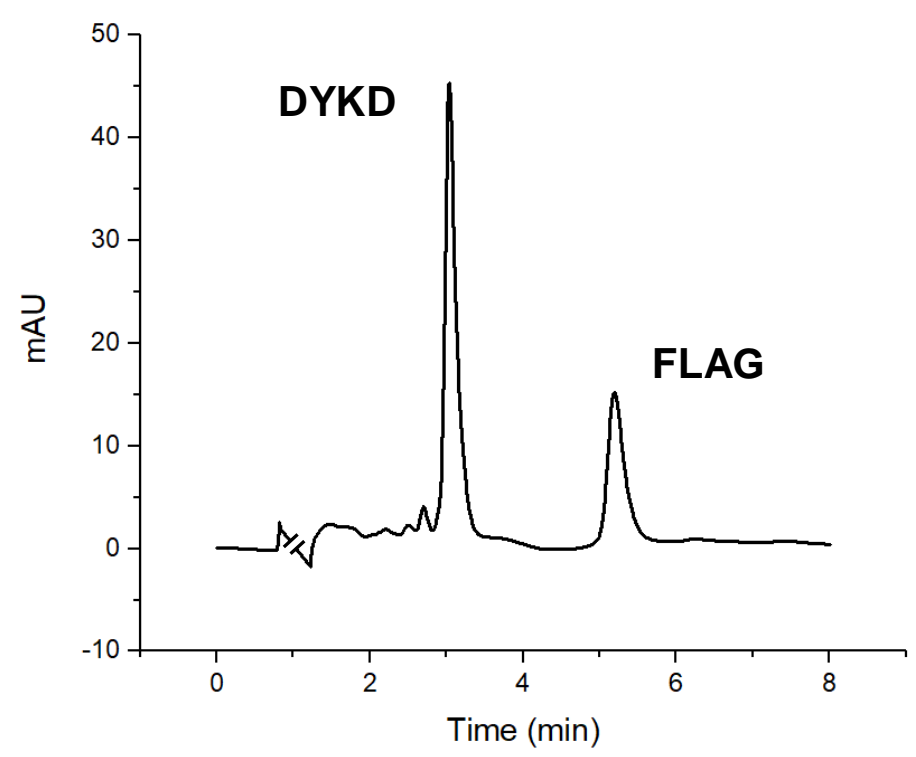

Figure S1. HPLC-DAD chromatogram for a mixture of peptides DYKD and DYKDDDDK (5 mg L1) in water/TBA $1 \%(w / v)$.

\subsection{Peptide GRGDNP}

Chromatographic separation was done with an ZORBAX SB- $\mathrm{C}_{18}$ analytical column $(4.6 \times 150 \mathrm{~mm}, 3.5 \mu \mathrm{m})$ from Agilent at $30^{\circ} \mathrm{C}$. The mobile phase was a mixture of solvent A (water/trifluoroacetic acid, TFA $0.1 \%(v / v)$ ) and solvent B (methanol/trifluoroacetic acid, TFA $0.1 \%(v / v))$ and used according to the following gradient programme: $90 \%$ A $(0-8$ $\min ), 90-10 \% A(8-8.5 \mathrm{~min}), 10 \% \mathrm{~A}(8.5-10 \mathrm{~min}), 10-90 \% \mathrm{~A}(10-10.5 \mathrm{~min})$ and $90 \% \mathrm{~A}$ (10.5-20 min). The flow rate was $1 \mathrm{~mL} \mathrm{~min}^{-1}$ and the injected volume $50 \mu \mathrm{L}$.

\subsection{Peptide YPYDVPDYA}

Chromatographic separation was done with an ACE Excel 2 C18-PFP analytical column $(100 \mathrm{~mm} \times 2.1 \mathrm{~mm}, 2 \mu \mathrm{m})$ from ACE at $30^{\circ} \mathrm{C}$. The mobile phase was a mixture of solvent $\mathrm{A}$ (water/trifluoroacetic acid, TFA $0.1 \%(v / v)$ ) and solvent $\mathrm{B}$ (acetonitrile 
trifluoroacetic acid, TFA $0.1 \%(v / v))$ and used according to the following gradient programme: $80-65 \% \mathrm{~A}(0-10 \mathrm{~min})$. The flow rate was $0.25 \mathrm{~mL} \mathrm{~min}^{-1}$ and the injected volume $5 \mu \mathrm{L}$.

\section{S4. Hierarchically molecularly imprinted polymer synthesis}

Hierarchically molecularly imprinted polymers (MIPs) were synthesized using functionalized silica beads with the peptide DYKDC (Si-DM-Pept in the case of MIP-DM and Si-AZA-Pept in the case of MIP-AZA) as sacrificial scaffolds. In the case of the nonimprinted polymers (NIP), functionalized iodoacetylated silica beads Si-DM-IAc (NIPDM) and Si-AZA-lac (NIP-AZA) were chosen as sacrificial supports.

Table S2. Optimized composition of hierarchically imprinted polymer using different template:functional monomer:cross-linker ratios (T:FM:CL, molar ratio).

\begin{tabular}{|c|c|c|c|c|}
\hline Polymer & MIP-DM & NIP-DM & MIP-AZA & NIP-AZA \\
\hline \multirow{2}{*}{ Silica support } & Si-DM-Pept & Si-DM-IAc & Si-AZA-Pept & Si-AZA-IAC \\
\hline & \multicolumn{2}{|c|}{$346 \mathrm{mg}$} & \multicolumn{2}{|c|}{$352 \mathrm{mg}$} \\
\hline EAMA & \multicolumn{2}{|c|}{$0.117 \mathrm{mmol}$} & \multicolumn{2}{|c|}{$0.117 \mathrm{mmol}$} \\
\hline EDMA & \multicolumn{2}{|c|}{$0.59 \mathrm{mmol}$} & \multicolumn{2}{|c|}{$0.71 \mathrm{mmol}$} \\
\hline DMSO & \multicolumn{2}{|c|}{$80 \mu \mathrm{L}$} & \multicolumn{2}{|c|}{$80 \mu \mathrm{L}$} \\
\hline ABDV & \multicolumn{2}{|c|}{$0.04 \mathrm{mmol}$} & \multicolumn{2}{|c|}{$0.04 \mathrm{mmol}$} \\
\hline T:FM:CL & $0.6: 4: 20$ & - & $0.4: 4: 24$ & - \\
\hline
\end{tabular}

S5. Molecularly imprinted solid phase extraction (MISPE) for cross-reactivity studies

Solid-phase extraction cartridges ( $1 \mathrm{~mL}$, Varian, Palo Alto, CA, USA) were packed with $25 \mathrm{mg}$ of hierarchically imprinted MIP-AZA or the corresponding NIP-AZA. The cartridges were equilibrated with $10 \mathrm{~mL}$ of $\mathrm{MeOH}$ and $10 \mathrm{~mL}$ of HEPES buffer $(100 \mathrm{mM}$, $\mathrm{pH}$ 7.5). The peptide solution, containing $1 \mathrm{~mL}$ of peptide GRGDNP or peptide YPYDVPDYA at $5 \mathrm{mg} \mathrm{L}^{-1}$ in HEPES buffer was percolated at a constant flow rate of 0.4 $\mathrm{mL} \mathrm{min}^{-1}$ with the aid of an 8-channel Ismatec ISM936D peristaltic pump (Oak Harbor, WA, US). Then, the cartridges were rinsed with $3 \mathrm{~mL}$ of water to remove non-specifically retained compounds and the peptides were eluted with $1 \mathrm{~mL}$ water/tetrabutylammonium hydrogensulfate (TBA) $1 \%(\mathrm{w} / \mathrm{v})$. The eluates from the MISPE column were injected into the HPLC system for analysis.

S6. Methods and models of computational study of DYKDC peptide/EAMA Complex, and DYKD and DYKDDDDK peptides

\subsection{Molecular Systems}


We performed extensive computational molecular modeling of three systems formed by peptides comprising residues 1) DYKD in water, 2) DYKDDDDK (FLAG) in water, and 3) DYKDC bound to $\mathrm{N}$-(2-aminoethyl)methacrylamide hydrochloride (EAMA) in dimethyl sulfoxide (DMSO). Each peptide chain was built using the LEaP module within the Amber 14.0 program. $^{5}$

\subsection{Molecular induced fit docking (IFD) with standard precision (SP)}

A representative DYKD peptide structure, obtained from the molecular dynamics (MD) simulation as described in Molecular Dynamics Simulations (see Manuscript), was used to generate a model of DYKDC bound to EAMA using the Induced Fit Docking (IFD) module through Glide and Prime of Schrödinger-Maestro 2018-3. ${ }^{6}$ First, LigPrep in Schrödinger-Maestro 2018-36 was used to prepare the EAMA ligand using the default parameters. EAMA initial structure was obtained as described below in Parameterization of EAMA Compound and Modified CYS Residue section. Secondly, Glide docking was carried out for EAMA. Then, the side chains were refined and optimized within $5.0 \AA$ of EAMA poses using Schrödinger Prime. Finally, the Glide SP redocking was performed using the default parameters. The 14 top-ranked EAMA poses were output and sorted by IFD score in the range of $-17.559 \mathrm{kcal} \mathrm{mol}^{-1}$ to $-14.630 \mathrm{kcal} \mathrm{mol}^{-1}$. Over $75 \%$ of the EAMA poses interact with either D4 and/or C5 of the DYKDC peptide. The 5 top-ranked EAMA poses were docked at D4 and/or C5 selecting EAMA pose 3 that interacts with D4 and C5 (IFD score of $-16.869 \mathrm{kcal} \mathrm{mol}^{-1}$ ) as the initial structure to conduct MD simulation.

\subsection{Parameterization of EAMA compound and modified CYS residue}

The force field parameter for EAMA to be used for MD simulation, which has positive charge (1+), was obtained using the following protocol: 1) the geometry of the molecule, drawn using VIDA ${ }^{7}$ program, was optimized using Quantum Mechanics Semi-empirical (QMS) minimization; 2) all EAMA atomic partial charges were computed with the AM1BCC semi-empirical method as implemented in the Amber 14.0 Antechamber programs; 5,8 and 3 ) the parameterization of the ligand atoms were done using the GAFF force field. ${ }^{5}$ Visual Molecular Dynamics (VMD), ${ }^{9} \mathrm{PyMOL}^{10}$ and VIDA $^{7}$ programs were used for further structure visualization and drawing. The Amber force field for the modified C-terminus cysteine residue on the thiol group (i.e., the hydrogen atom of the thiol group was replaced by a methyl group) was obtained by 1) keeping the same parameters for all backbone atoms and beta carbon atom of the standard C-terminus cysteine residue; and 2) adjusting the charges for the modified thiol group based on AM1- 
BCC semi-empirical method calculations. The charges and parameters are available upon request.

\subsection{Molecular dynamics simulations setups}

We performed extensive, 1 us MD simulation for each system using the FF14SB allatom Amber force field ${ }^{5,11}$ and the TIP3P water $^{12}$ or the DMSO models in all calculations. The DMSO solvent box, created by John Dalmaris ${ }^{13}$ and reported on Richard Bryce's group website, ${ }^{13}$ based on atomic parameters for the Amber force field developed by Fox and Kollman ${ }^{14}$ was used as well. During the MD simulations, all present titratable groups in the peptides were treated charged. The three systems were initially minimized using the Steepest Descent and Conjugate Gradient methods to remove all the possible unfavorable interactions from the built peptides models. Weak restraints on the peptides (force constants 2 to $1 \mathrm{kcal} \mathrm{mol}^{-1} \AA^{-2}$ ) were imposed. Then, the apo-peptide systems DYKD and DYKDDDDK (FLAG) were heated from $0 \mathrm{~K}$ until $1500 \mathrm{~K}$ or until $2000 \mathrm{~K}$, respectively, and then cooled slowly until $300 \mathrm{~K}$ using Langevin dynamics ${ }^{15}$ at constant volume. They were heated to $1500 \mathrm{~K}$ for $1 \mathrm{~ns}$ (or $2000 \mathrm{~K}$ for $800 \mathrm{ps}$ ) with a Langevin collision frequency of $\mathrm{y}=5.0 \mathrm{ps}^{-1}$, and cooled down slowly for other $1.7 \mathrm{~ns}$ (or $1.9 \mathrm{~ns}$ ) with a Langevin collision frequency of $\mathrm{Y}=5.0 \mathrm{ps}^{-1}$. Three (or one) sodium ions were added to each system, respectively, to neutralize the simulation cell. Then, the volume was allowed to change freely and the temperature was kept constant with a Langevin collision frequency of $\mathrm{Y}=5.0 \mathrm{ps}^{-1}$, and isotropic Berendsen regulation ${ }^{16}$ (1 atm) with a Berendsen coupling constant of taup $=5.0 \mathrm{ps}$. The weak positional restrains on the peptides was gradually reduced from $0.5 \mathrm{kcal} \mathrm{mol}^{-1} \AA^{-2}$ to $0.1 \mathrm{kcal} \mathrm{mol}^{-1} \AA^{-2}$ respectively, until the system was allowed to move freely. Non-bonded cutoffs of $9 \AA$ was used for the Lennard-Jones potentials and electrostatic interactions calculated using particlemesh Ewald (PME). The production MD simulation was carried out using the NPT ensemble and using Particle Mesh Ewald Molecular Dynamics (pmemd.MPI). In the production stage the temperature was maintained at $300 \mathrm{~K}$ using Langevin dynamics with a collision frequency of $Y=5.0 \mathrm{ps}^{-1}$. The isotropic Berendsen regulation ${ }^{16}$ (1 atm) with a Berendsen coupling constant of taup $=5.0$ ps was also used. The length of all bonds involving hydrogen atoms was kept fixed with the SHAKE algorithm. ${ }^{17}$ The pressure was kept fixed at $1 \mathrm{~atm}$. The equations of motion were integrated with a timestep of $2 \mathrm{fs}$. The coordinates were recorded at every $5 \mathrm{ps}$. The MD simulation of DYKDC peptide/EAMA complex system was set up as for the previous apo-peptides except for the heating protocol where the temperature was directly increased from $0 \mathrm{~K}$ to $300 \mathrm{~K}$ using Langevin dynamics with collision frequency of $\mathrm{Y}=5.0 \mathrm{ps}^{-1}$. The initial structure of the DYKDC/EAMA complex was obtained as described above in Molecular Induced Fit 
Docking (IFD) with Standard Precision (SP) section. In addition, there was a strong positional restraint on Cys 5 of DYKDC peptide (force constant $100 \mathrm{kcal} \mathrm{mol}^{-1} \AA^{-2}$ ) during the MD simulation to mimic the immobilization of the peptide C-terminus thiol group covalently bond to the silica. All MD simulations and analysis were performed using Amber, ${ }^{5,18}$ Simulaid, ${ }^{19}$ and VIDA ${ }^{7}$ programs.

\section{RESULTS AND DISCUSSION SECTION}

\section{S7. Equations}

The amount of immobilized ligand (expressed as degree of functionalization in mmol $\mathrm{g}^{-1}, \mathrm{D}_{\mathrm{f}}$ ) on the silica surface was estimated by elemental microanalysis data, more precisely from the change in carbon content $(\Delta \% \mathrm{C})$ compared to the preceding step (Equation S1):

$$
D_{f}=\Delta C \% \cdot \frac{F}{m_{C} \cdot N_{C}}
$$

Where $D_{f}$ is the degree of functionalization $\left(\mathrm{mmol} \mathrm{g}^{-1}\right), \Delta \% \mathrm{C}$ is the difference in the carbon content versus the preceding step, $\mathrm{F}$ is the conversion factor (10) required to express the result in $\mathrm{mmol} \mathrm{g}^{-1}, \mathrm{~m}_{\mathrm{C}}$ is the atomic weight of carbon $\left(12 \mathrm{~g} \mathrm{~mol}^{-1}\right)$ and $\mathrm{N}_{\mathrm{C}}$ the number of carbon atoms presented in the coupled ligand.

The coupling yield expressed in \% was calculated applying Equation S2:

$$
\text { Yield }=\frac{X_{C}}{X_{A}} \cdot 100
$$

Where $X_{C}$ is the amount of ligand attached to the surface (mmol) and $X_{A}$ is the total amount of available ligand of the preceding step ( $\mathrm{mmol}$ ).

\section{S8. Characterization of derivatized silica beads}

\subsection{Silane derivatization}


a

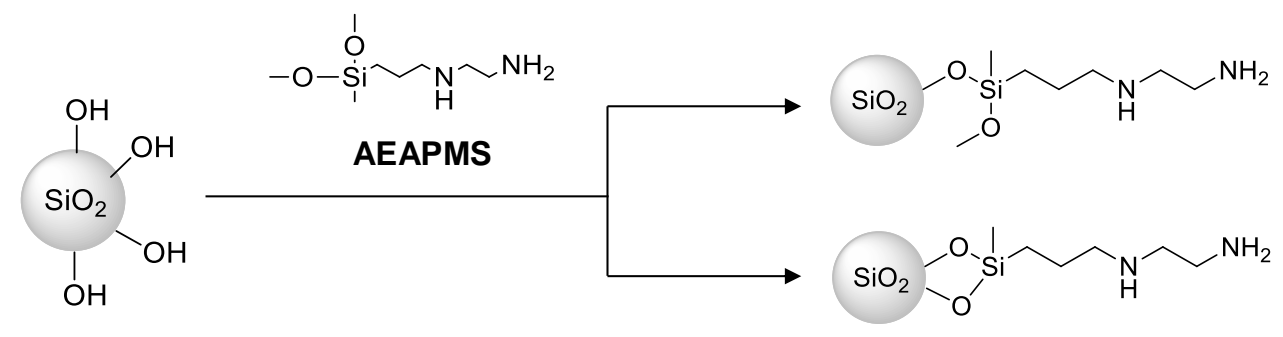

b<smiles>Oc1ccc(O)c(O)c1O</smiles>

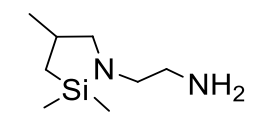

AETAZS

Figure S2. Functionalization scheme of silanization step using (a) 3-(2Aminoethylamino)propyldimethoxymethylsilane (AEAPMS) with (1) one or (2) two methoxy groups grafted to the silica surface and (b) $\mathrm{N}$-(2-aminoethyl)-2,2,4-trimethyl-1-aza-2silacyclopentane (AETAZS).

\section{A) Derivatization using 3-(2-Aminoethylamino)propyldimethoxymethylsilane (AEAPMS)}

Table S3. Elemental microanalysis results and degree of functionalization $\left(D_{f}\right.$, expressed as $\mathrm{mmol}$ $\mathrm{g}^{-1}$ calculated according to Eq. S1) corresponding to silica beads derivatized using 3-(2aminoethylamino)propyldimethoxymethylsilane (AEAPMS) under different experimental conditions.

\begin{tabular}{ccccc}
\hline Material & $\% \mathbf{C}$ & $\% \mathbf{H}$ & $\% \mathbf{N}$ & $\mathbf{D}_{\mathbf{f}}\left(\mathbf{m m o l ~ g}^{-1}\right)$ \\
\hline SiOH & 0.05 & 0.27 & 0.09 & - \\
\hline Si-DMPTSA1 & 2.03 & 0.66 & 0.68 & 0.24 \\
\hline Si-DMPTSA2 & 2.25 & 0.68 & 0.71 & 0.27 \\
\hline Si-DMPTSA3 & 2.32 & 0.7 & 0.73 & 0.28 \\
\hline Si-DMPTSA4 & 3.48 & 0.86 & 1.04 & 0.41 \\
\hline Si-DMRT $^{*}$ & 1.78 & 0.60 & 0.68 & 0.25 \\
\hline
\end{tabular}

*According to the experimental ratio between carbon and nitrogen content, all the samples were calculated assuming only one methoxy group grafted to the silica surface, whereas $D_{f}$ of Si-DMRT was calculated assuming two methoxy groups grafted to the silica surface.

As described in Table S3, when comparing the optimum $2 \mathrm{~h}$ (Si-DMPTSA1) versus $16 \mathrm{~h}$ (Si-DMPTSA4) reaction times, under the same experimental conditions, it can be noticed that longer times yielded a higher functionalization degree (Si-DMPTSA4, $0.41 \mathrm{mmol} \mathrm{g}^{-1}$ ). Interestingly, when performing silane coupling reaction at room temperature and in the absence of catalyst during $24 \mathrm{~h}$ (Si-DMRT), a decrease in the grafting content was observed $\left(0.25 \mathrm{mmol}^{-1}\right)$ compared with Si-DMPTSA4. 


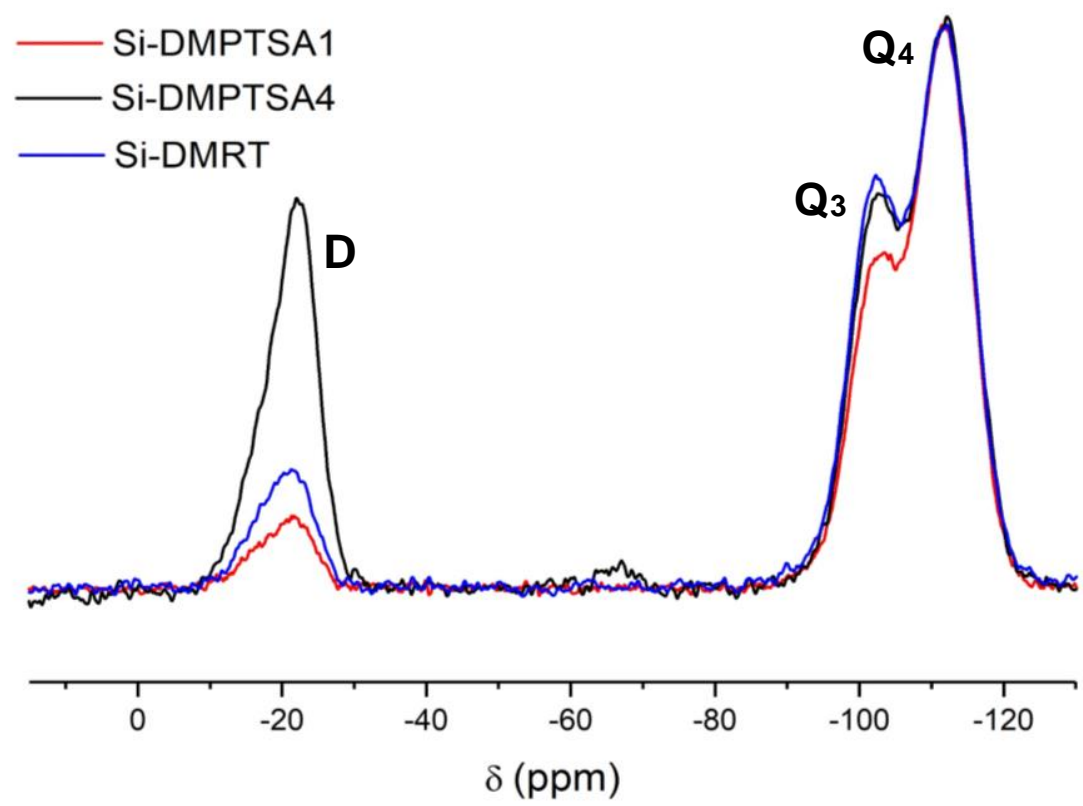

Figure S3. ${ }^{29} \mathrm{Si} \mathrm{CP} / \mathrm{MAS}$ NMR spectra of silica particles functionalized with silane AEAPMS using different conditions: Si-DMPTSA1 (3.75 mmol g-1 $110^{\circ} \mathrm{C}$, PTSA, $2 \mathrm{~h}$ ), Si-DMPTSA4 (3.75 mmol $\left.\mathrm{g}^{-1}, 110 \stackrel{\circ}{\circ} \mathrm{C}, \mathrm{PTSA}, 16 \mathrm{~h}\right)$ and Si-DMRT (3.75 $\left.\mathrm{mmol} \mathrm{g}^{-1}, 25 \stackrel{\circ}{\circ} \mathrm{C}, 24 \mathrm{~h}\right)$.

Table S4. Elemental microanalysis results and degree of functionalization $\left(D_{f}\right.$, expressed as mmol $\mathrm{g}^{-1}$ calculated according to Eq. S1) of three different batches of Si-DMPTSA1.

\begin{tabular}{ccccc}
\hline Batch & $\% \mathbf{C}$ & $\% \mathbf{H}$ & $\% \mathbf{N}$ & $\mathbf{D}_{\mathbf{f}}\left(\mathbf{m m o l ~}^{-1}\right)$ \\
\hline Si-DMPTSA 1A & 2.03 & 0.66 & 0.68 & 0.24 \\
\hline Si-DMPTSA 1B & 2.09 & 0.66 & 0.63 & 0.25 \\
\hline Si-DMPTSA 1C & 2.51 & 0.73 & 0.75 & 0.30
\end{tabular}

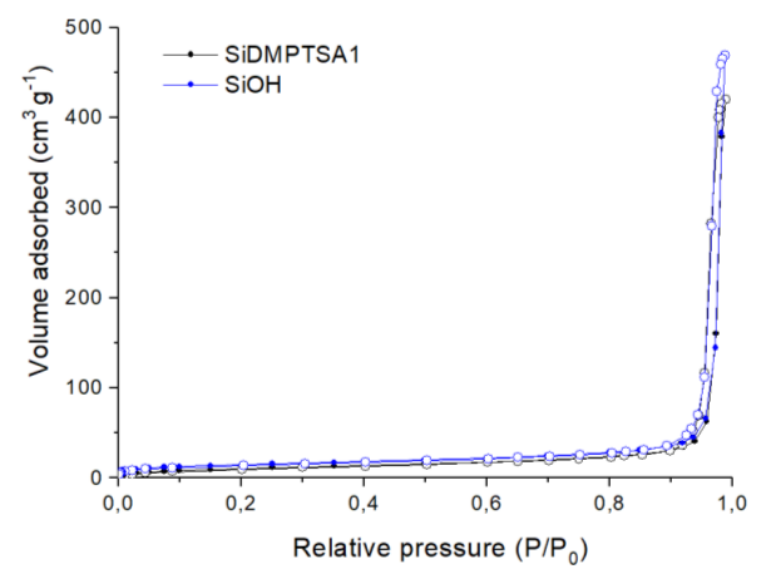

Figure S4. Nitrogen adsorption isotherms corresponding to Si-DMPTSA1 and rehydroxilated silica $(\mathrm{SiOH})$ samples. 


\section{B) Derivatization using $\quad \mathrm{N}$-(2-aminoethyl)-2,2,4-trimethyl-1-aza-2- silacyclopentane (AETAZS)}

Table S5. Elemental microanalysis results and degree of functionalization $\left(D_{f}\right.$, expressed as mmol $\mathrm{g}^{-1}$ calculated according to Eq. S1) corresponding to silica beads derivatized using $\mathrm{N}$-(2aminoethyl)-2,2,4-trimethyl-1-aza-2-silacyclopentane (AETAZS).

\begin{tabular}{ccccc}
\hline Material & \%C & \%H & \%N & $\mathbf{D}_{\mathbf{f}}\left(\mathbf{m m o l ~ g}^{-1}\right)$ \\
\hline SiOH & 0.05 & 0.27 & 0.09 & - \\
\hline Si-AZA1 & 1.15 & 0.46 & 0.35 & 0.12 \\
\hline Si-AZA2 & 1.21 & 0.51 & 0.36 & 0.13 \\
\hline Si-AZA3 & 1.27 & 0.53 & 0.37 & 0.13
\end{tabular}

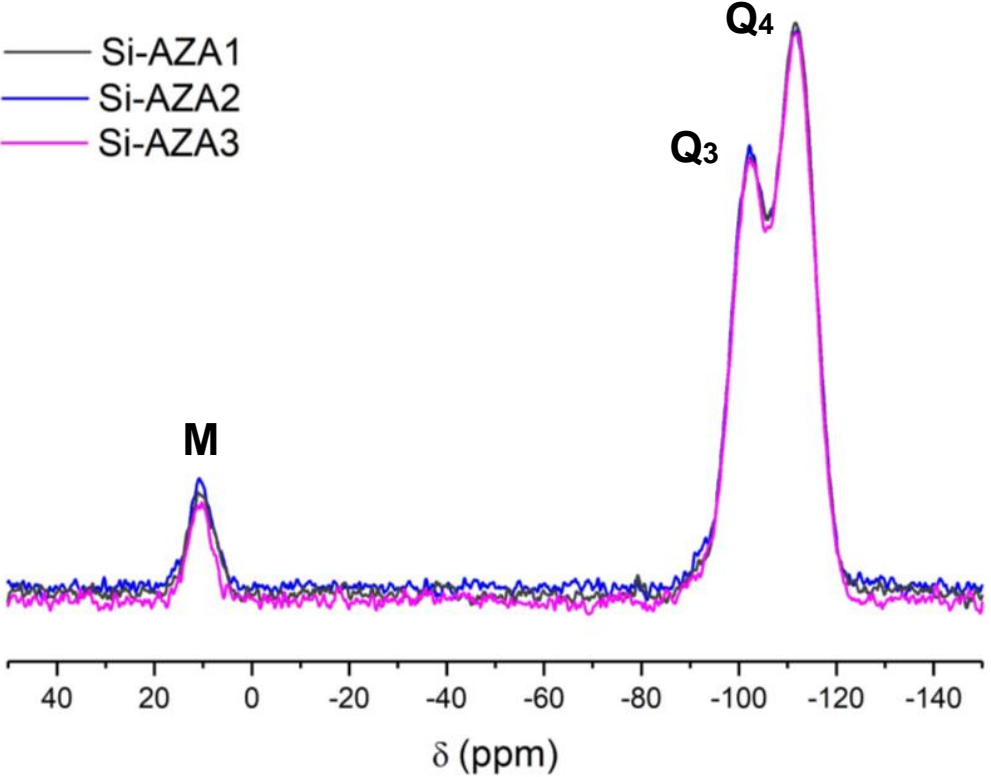

Figure S5. ${ }^{29} \mathrm{Si} \mathrm{CP} / \mathrm{MAS}$ NMR spectra of silica particles functionalized with silane AETAZS using different con-centration levels $3.75 \mathrm{mmol}$ (Si-AZA1), $7.5 \mathrm{mmol}$ (Si-AZA2) and $11.25 \mathrm{mmol} \mathrm{g}^{-1}$ (SiAZA3).

The same intensity in Q3 signal indicates a similar extent of surface silanol condensation reaction (note that this signal is higher than for the sample Si-DMPTSA4, functionalized with AEAPMS). On its turn, silane coupling gives rise to a signal at about 13 ppm, called M signal, associated to the monofunctional silane grafting, that exhibits similar intensity in the three samples being unable to distinguish the changes in silane content. ${ }^{20}$ 
Table S6. Elemental microanalysis results and degree of functionalization $\left(\mathrm{D}_{\mathrm{f}}\right.$, expressed as $\mathrm{mmol}$ $\mathrm{g}^{-1}$ calculated according to Eq. S1) of different batches of Si-AZA1.

\begin{tabular}{ccccc}
\hline Batch & $\% \mathbf{C}$ & $\% \mathbf{H}$ & $\% \mathbf{N}$ & $\mathbf{D}_{\mathbf{f}}\left(\mathbf{m m o l ~}^{-1}\right)$ \\
\hline Si-AZA 1A & 1.36 & 0.58 & 0.48 & 0.142 \\
\hline Si-AZA 1B & 1.36 & 0.57 & 0.48 & 0.142 \\
\hline Si-AZA 1C & 1.35 & 0.58 & 0.49 & 0.141 \\
\hline Si-AZA 1D & 1.15 & 0.46 & 0.35 & 0.12 \\
\hline
\end{tabular}

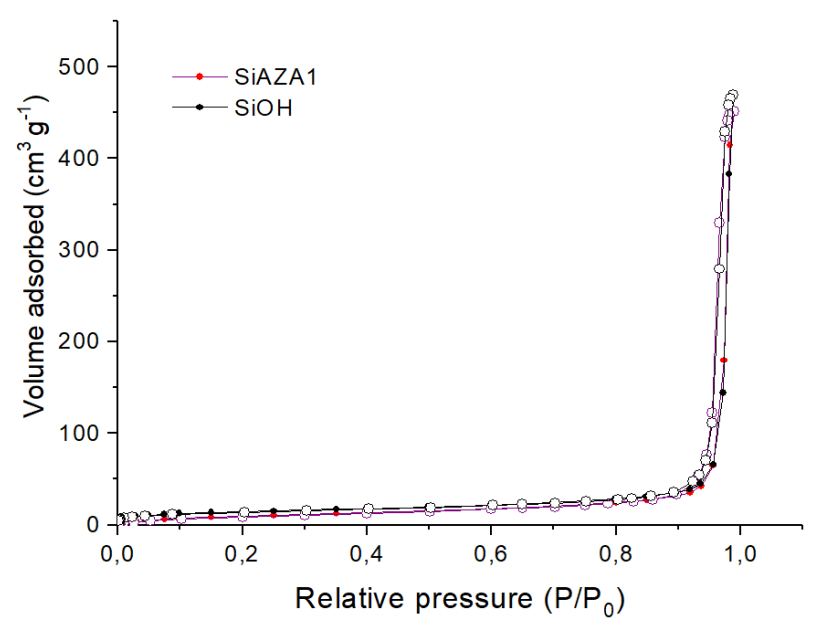

Figure S6. Nitrogen adsorption isotherms corresponding to Si-AZA1 and rehydroxylated silica (SiOH) samples.
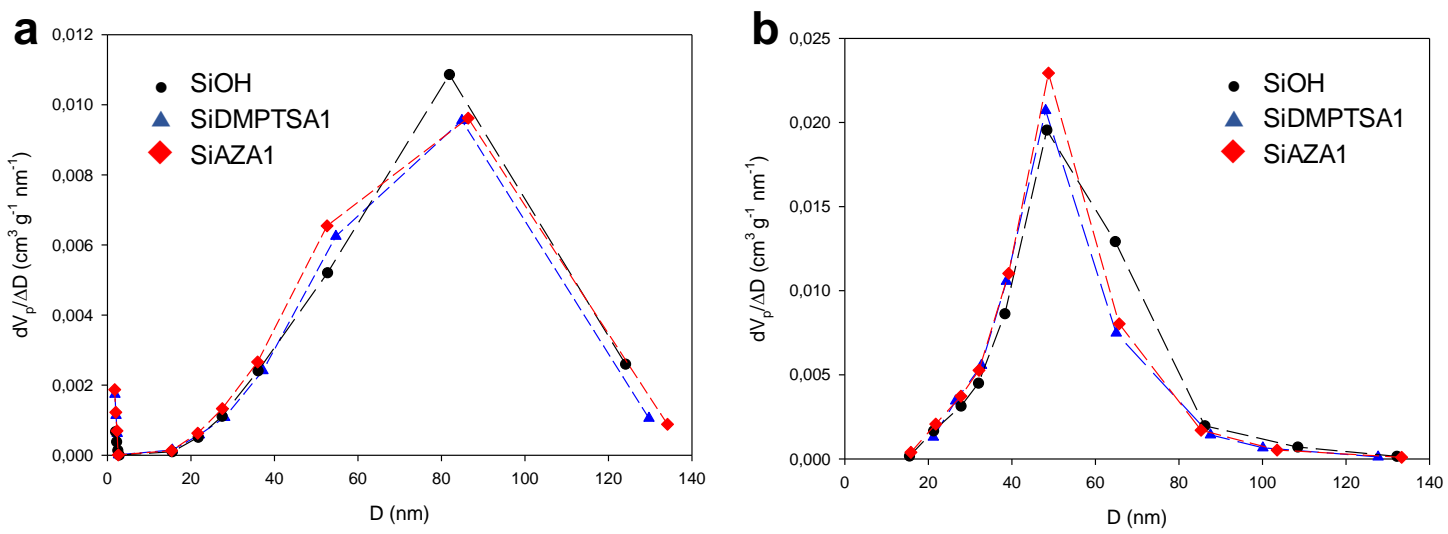

Figure S7. Pore size distribution curves obtained from the adsorption (a) and desorption (b) branches of the isotherms for (black) SiOH, (blue) SiDMPTSA1 and (red) SiAZA1 samples. 
a

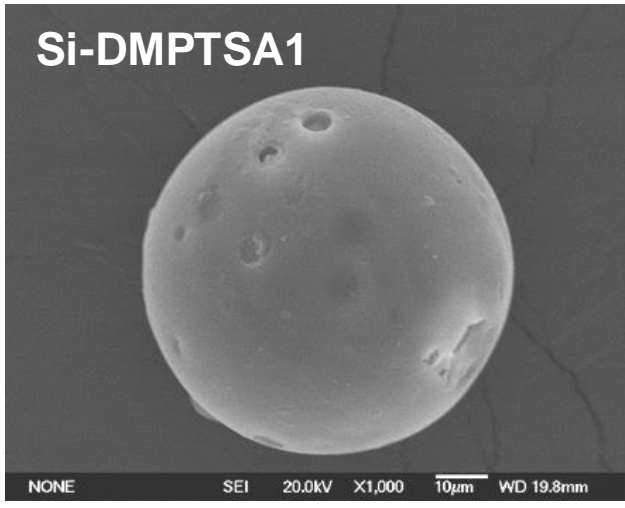

b

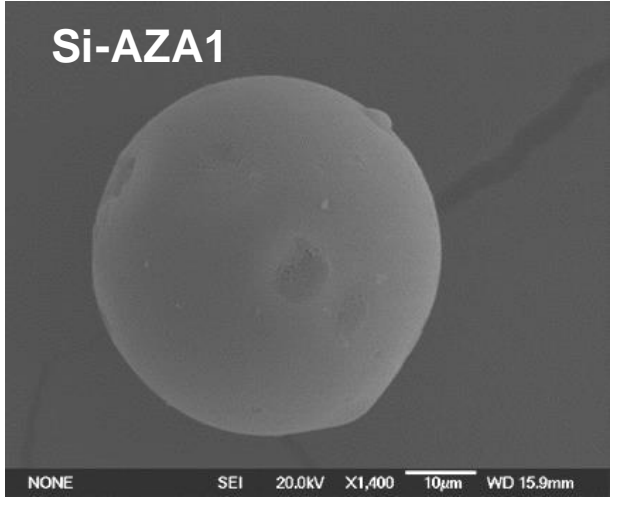

Figure S8. Scanning electron micrographs of amino-functionalized particles at optimum conditions. (a) Si-DMPTSA1 (3.75 mmol AEAPMS g ${ }^{-1}, 110 \stackrel{\circ}{\circ}$, PTSA, 2 h), (b) Si-AZA1 (3.75 mmol AETAZS g ${ }^{-1}, 25^{\circ} \mathrm{C}, 24 \mathrm{~h}$ ).

\section{2. lodoacetylation of amino-modified particles}

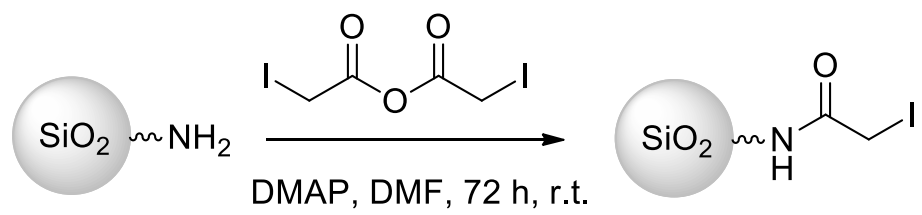

Figure S9. Functionalization scheme of iodoacetylation of amino-modified silica beads.

Functionalization degree of iodoacetamide groups immobilized on silica beads was estimated by applying the Equation $S 1$ based on the change in the carbon content versus the previous step (Si-DMPTSA1 and Si-AZA1, respectively) to the final product (designed as Si-DM-IAc-X or Si-AZA-IAc-X).

Table S7. Elemental microanalysis results and degree of functionalization $\left(D_{f}\right)$ obtained after iodoacetylation reaction of Si-DMPTSA1 samples of different batches.

\begin{tabular}{cccccc}
\hline Batch & $\% \mathbf{C}$ & $\% \mathbf{H}$ & $\% \mathbf{N}$ & $\Delta \% \mathbf{C}$ & $\mathbf{D}_{\mathbf{f}}\left(\mathbf{m m o l ~ g}^{-1}\right)$ \\
\hline Si-DM-IAc-0 & 2.41 & 0.64 & 0.69 & 0.32 & 0.13 \\
\hline Si-DM-IAC-1 & 2.44 & 0.66 & 0.74 & 0.41 & 0.17 \\
\hline Si-DM-IAC-2 & 2.84 & 0.75 & 0.74 & 0.33 & 0.14 \\
\hline Si-DM-IAC-3 & 2.82 & 0.72 & 0.75 & 0.31 & 0.13 \\
\hline Si-DM-IAC-4 & 2.88 & 0.74 & 0.77 & 0.37 & 0.15 \\
\hline Si-DM-IAC-5 & 2.98 & 0.75 & 0.80 & 0.47 & 0.20 \\
\hline
\end{tabular}


Table S8. Elemental microanalysis results and degree of functionalization $\left(D_{f}\right)$ obtained after iodoacetylation reaction of Si-AZA1 samples of different batches.

\begin{tabular}{cccccc}
\hline Batch & $\% \mathbf{C}$ & $\% \mathbf{H}$ & $\% \mathbf{N}$ & $\Delta \% \mathbf{C}$ & $\mathbf{D}_{\mathbf{f}}\left(\mathbf{m m o l ~ g}^{-1}\right)$ \\
\hline Si-AZA-IAC-1 & 1.54 & 0.53 & 0.45 & 0.18 & 0.08 \\
\hline Si-AZA-IAc-2 & 1.60 & 0.56 & 0.45 & 0.25 & 0.10 \\
\hline Si-AZA-IAC-3 & 1.61 & 0.54 & 0.45 & 0.26 & 0.11
\end{tabular}

\subsection{Peptide DYKDC coupling}

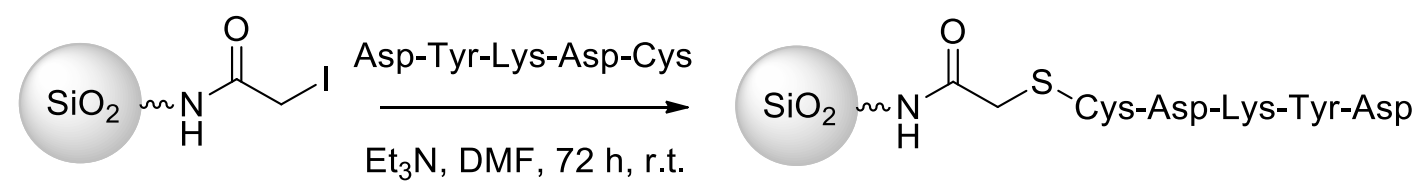

Figure S10. Functionalization scheme of peptide DYKDC coupling to iodoacetylated silica beads.

Table S9. Elemental microanalysis results and degree of functionalization $\left(D_{f}\right)$ obtained after peptide DYKDC immobilization on iodoacetylated Si-DM-IAc particles.

\begin{tabular}{ccccccc}
\hline Batch & $\% \mathbf{C}$ & $\% \mathbf{H}$ & $\% \mathbf{N}$ & $\% \mathbf{S}$ & $\Delta \% \mathbf{C}$ & $\mathbf{D}_{\mathbf{f}}\left(\mathbf{m m o l ~ g}^{-1}\right)$ \\
\hline Si-DM-Pept-0 & 4.03 & 0.85 & 1.34 & 0.17 & 1.62 & 0.052 \\
\hline Si-DM-Pept-1 & 3.93 & 0.85 & 1.28 & 0.20 & 1.49 & 0.048 \\
\hline Si-DM-Pept-2 & 4.55 & 0.91 & 1.25 & 0.23 & 1.71 & 0.055 \\
\hline Si-DM-Pept-3 & 4.50 & 0.98 & 1.23 & 0.21 & 1.68 & 0.054 \\
\hline Si-DM-Pept-4 & 4.39 & 0.95 & 1.22 & 0.21 & 1.51 & 0.048 \\
\hline Si-DM-Pept-5 & 4.38 & 0.95 & 1.25 & 0.23 & 1.4 & 0.045 \\
\hline
\end{tabular}

Table S10. Elemental microanalysis results and degree of functionalization $\left(D_{f}\right)$ obtained after peptide DYKDC immobilization on iodoacetylated Si-AZA-IAc particles.

\begin{tabular}{ccccccc}
\hline Batch & $\% \mathbf{C}$ & $\% \mathbf{H}$ & $\% \mathbf{N}$ & $\% \mathbf{S}$ & $\Delta \% \mathbf{C}$ & $\mathbf{D}_{\mathbf{f}}\left(\mathbf{m m o l ~ g}^{-1}\right)$ \\
\hline Si-AZA-Pept-1 & 2.57 & 0.61 & 0.72 & 0.09 & 1.03 & 0.033 \\
\hline Si-AZA-Pept-2 & 2.82 & 0.72 & 0.69 & 0.12 & 1.22 & 0.039 \\
\hline Si-AZA-Pept-3 & 2.67 & 0.66 & 0.68 & 0.11 & 1.06 & 0.034 \\
\hline
\end{tabular}




\section{S9. Hierarchically imprinted MIP-AZA polymers}

a

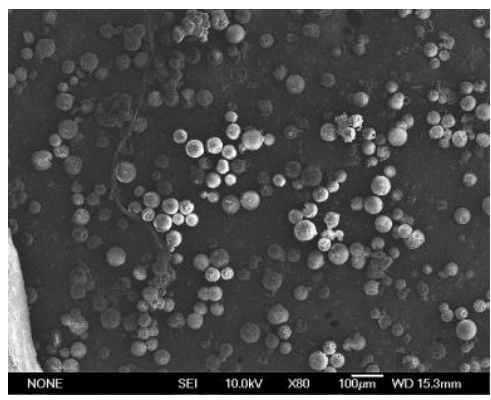

b

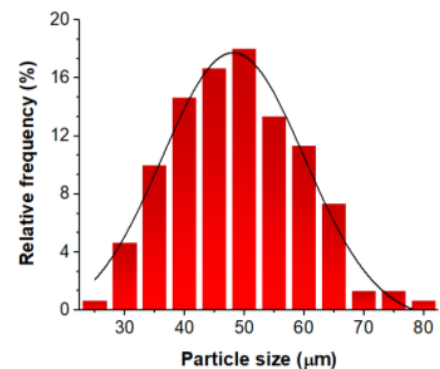

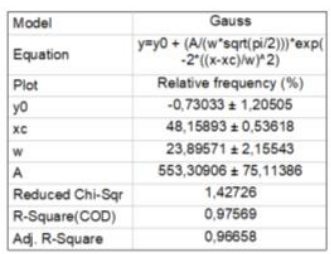

Figure S11. (a) Scanning electron micrographs of MIP-AZA particles and (b) particle size distribution adjusted to a Gaussian model (OriginPro 2017).

Table S11. Imprinting factors (calculated as $\mathrm{R}_{\mathrm{MIP}} / \mathrm{R}_{\mathrm{NIP}}$ ) obtained for the DYKD and FLAG peptides in the MIPs prepared in this work using the optimized MISPE protocol.

\begin{tabular}{|c|c|c|}
\hline Polymer & Analyte & IF \\
\hline MIP-DM & \multirow{3}{*}{ DYKD } & 2.0 \\
\hline MIP-AZA & & 2.0 \\
\hline MSP8* & & 12.8 \\
\hline MIP-DM & \multirow{3}{*}{ FLAG } & 3.2 \\
\hline MIP-AZA & & 21.3 \\
\hline MSP8* & & 3.3 \\
\hline
\end{tabular}

*Non-hierarchically imprinted polymer (MSP8) was synthesized using DYKD as template molecule as reported previously. ${ }^{21}$

\section{S10. Computational study of DYKDC peptide/EAMA complex, and DYKD and DYKDDDDK peptides}
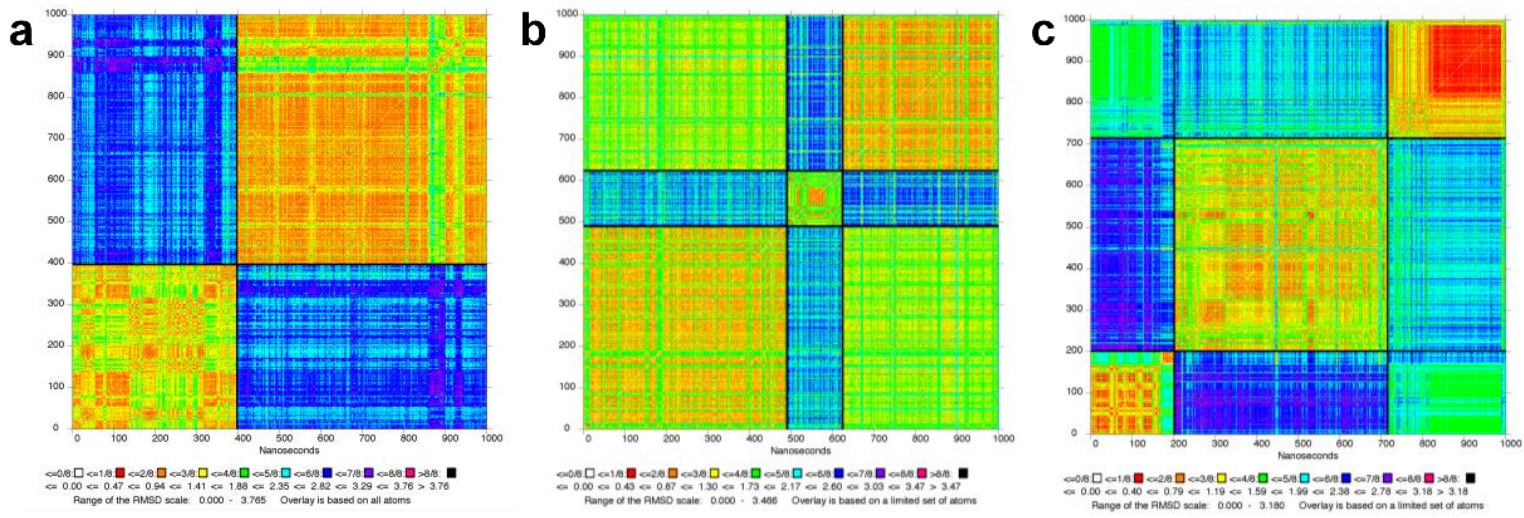

Figure S12. Cluster analysis of (a) DYKDC peptide/EAMA complex in DMSO: the two main conformations are depicted: Cluster $1(\sim 40 \%)$ and Cluster $2(\sim 60 \%)$; (b) DYKD peptide in water: the three main conformations are depicted: Cluster $1(\sim 50 \%)$, Cluster $2(\sim 37 \%)$, and Cluster 3 ( 13\%); (c) DYKDDDDK (FLAG) peptide in water: the three main conformations are depicted: Cluster 1 ( $52 \%)$, Cluster 2 ( 28\%) and Cluster 3 ( 20\%). 


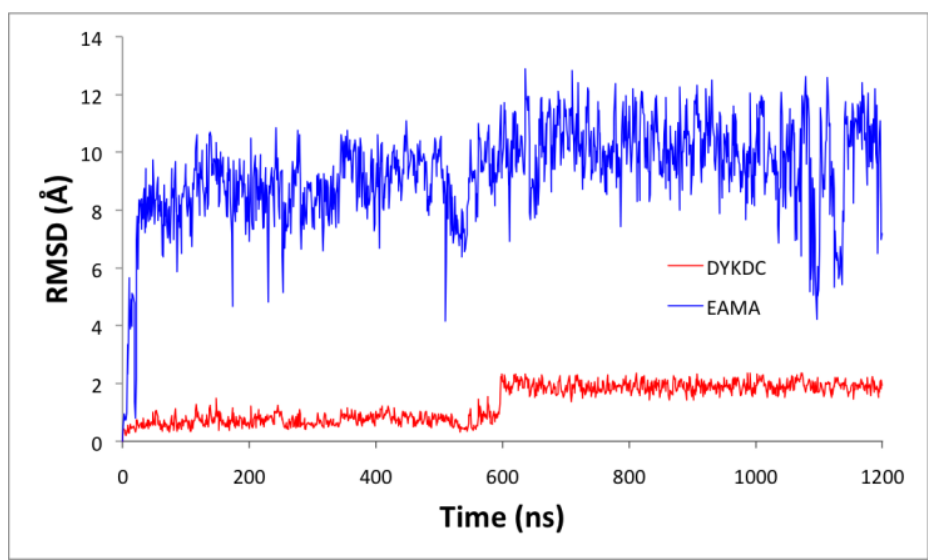

Figure S13. Computational study of DYKDC peptide/EAMA complex in DMSO. Root-meansquare deviation (RMSD) with respect to minimized initial structure backbone atoms.
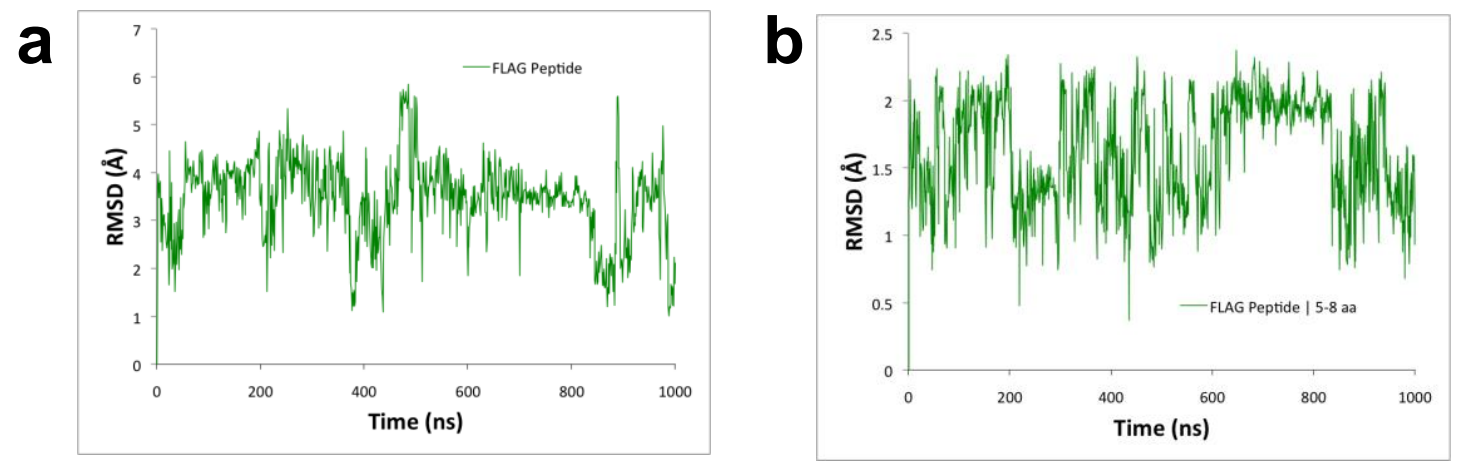

Figure S14. Computational study of DYKDDDDK (FLAG) peptide in water. Root-mean-square deviation (RMSD) of the FLAG peptide with respect to minimized initial structure backbone atoms: (a) aligned with respect to all residues; and (b) aligned with respect to residues 5 to 8 (DDDK). 
Table S12. Hydrogen bonds analysis for the DYKDC peptide/EAMA complex (Last $1 \mu \mathrm{s}$ MD simulation).

\begin{tabular}{|c|c|c|c|c|c|}
\hline Acceptor & DonorH & Donor & $\%$ Occupied & Distance $(\AA)$ & Angle $\left(^{\circ}\right)$ \\
\hline CYS@O* & EAMA@H1 & EAMA@N1 & 62.80 & 3.13 & 145.32 \\
\hline CYS@OXT* & EAMA@H1 & EAMA@N1\& & 74.50 & 2.97 & 151.06 \\
\hline \multirow[t]{3}{*}{ CYS@O } & EAMA@H4 & EAMA@N2\& & 38.80 & 2.77 & 155.48 \\
\hline & EAMA@H5 & EAMA@N2 & 34.20 & 2.80 & 152.40 \\
\hline & EAMA@H6 & EAMA@N2 & 23.90 & 2.75 & 158.74 \\
\hline \multirow[t]{3}{*}{ CYS@OXT } & EAMA@H4 & EAMA@N2 & 30.80 & 3.02 & 139.49 \\
\hline & EAMA@H5 & EAMA@N2 & 30.90 & 2.95 & 142.76 \\
\hline & EAMA@H6 & EAMA@N2 & 15.60 & 3.04 & 137.45 \\
\hline \multirow[t]{3}{*}{ ASP4@OD1* } & EAMA@H4 & EAMA@N2 & 17.20 & 2.74 & 163.43 \\
\hline & EAMA@H5 & EAMA@N2 & 9.20 & 2.73 & 162.12 \\
\hline & EAMA@H6 & EAMA@N2 & 22.90 & 2.72 & 164.08 \\
\hline \multirow[t]{3}{*}{ ASP4@OD2* } & EAMA@H4 & EAMA@N2 & 8.30 & 2.74 & 163.59 \\
\hline & EAMA@H5 & EAMA@N2 & 20.80 & 2.72 & 163.04 \\
\hline & EAMA@H6 & EAMA@N2 & 22.00 & 2.72 & 163.19 \\
\hline
\end{tabular}

${ }^{*} \mathrm{O}$ and OXT represent the carboxyl oxygen of the -COO- groups of D4 and C5. ${ }^{8} \mathrm{~N} 1$ and $\mathrm{N} 2$ represent the nitrogen of the $-\mathrm{NH}$ and $-\mathrm{NH}_{3}$ groups of EAMA, respectively. Hydrogen bonds were determined via the distance between the heavy atoms using a cutoff of $3.5 \AA$ and the angle between the acceptor and donor atoms using a cutoff of $120^{\circ}$. 
Table S13. Hydrogen bonds analysis for the DYKDC peptide/EAMA complex (Cluster 1, first 400 ns of last $1 \mu \mathrm{s}$ MD simulation).

\begin{tabular}{|c|c|c|c|c|c|}
\hline Acceptor & DonorH & Donor & $\%$ Occupied & Distance $(\AA ̊)$ & Angle $\left({ }^{\circ}\right)$ \\
\hline CYS@O* & EAMA@H1 & EAMA@N1\& & 75.44 & 3.06 & 148.08 \\
\hline CYS@OXT* & EAMA@H1 & EAMA@N1 & 62.66 & 2.99 & 149.03 \\
\hline \multirow[t]{3}{*}{ CYS@O } & EAMA@H4 & EAMA@N2\& & 45.86 & 2.79 & 152.22 \\
\hline & EAMA@H5 & EAMA@N2 & 34.34 & 2.84 & 146.87 \\
\hline & EAMA@H6 & EAMA@N2 & 14.04 & 2.78 & 158.30 \\
\hline \multirow[t]{3}{*}{ CYS@OXT } & EAMA@H4 & EAMA@N2 & 36.34 & 2.95 & 142.93 \\
\hline & EAMA@H5 & EAMA@N2 & 35.84 & 2.87 & 146.41 \\
\hline & EAMA@H6 & EAMA@N2 & 9.77 & 3.01 & 136.24 \\
\hline \multirow[t]{3}{*}{ ASP4@OD1* } & EAMA@H4 & EAMA@N2 & 7.02 & 2.71 & 164.58 \\
\hline & EAMA@H5 & EAMA@N2 & 9.77 & 2.72 & 162.06 \\
\hline & EAMA@H6 & EAMA@N2 & 22.81 & 2.72 & 163.88 \\
\hline \multirow[t]{3}{*}{ ASP4@OD2* } & EAMA@H4 & EAMA@N2 & 5.26 & 2.75 & 161.12 \\
\hline & EAMA@H5 & EAMA@N2 & 18.80 & 2.72 & 163.99 \\
\hline & EAMA@H6 & EAMA@N2 & 37.09 & 2.72 & 162.77 \\
\hline
\end{tabular}

${ }^{*} \mathrm{O}$ and OXT represent the carboxyl oxygen of the -COO- groups of D4 and C5. ${ }^{\circledR} \mathrm{N} 1$ and $\mathrm{N} 2$ represent the nitrogen of the $-\mathrm{NH}$ and $-\mathrm{NH}_{3}$ groups of EAMA, respectively. Hydrogen bonds were determined via the distance between the heavy atoms using a cutoff of $3.5 \AA$ and the angle between the acceptor and donor atoms using a cutoff of $120^{\circ}$. 
Table S14. Hydrogen bonds analysis for the DYKDC peptide/EAMA complex (Cluster 2, last 600 ns of last $1 \mu \mathrm{s}$ MD simulation).

\begin{tabular}{|c|c|c|c|c|c|}
\hline Acceptor & DonorH & Donor & $\%$ Occupied & Distance $(\AA)$ & Angle $\left({ }^{\circ}\right)$ \\
\hline CYS@O* & EAMA@H1 & EAMA@N1 & 54.41 & 3.19 & 142.79 \\
\hline CYS@OXT* & EAMA@H1 & EAMA@N1 & 82.36 & 2.96 & 152.09 \\
\hline \multirow[t]{3}{*}{ CYS@O } & EAMA@H4 & EAMA@N2 ${ }^{\&}$ & 34.11 & 2.76 & 158.40 \\
\hline & EAMA@H5 & EAMA@N2 & 34.11 & 2.76 & 156.10 \\
\hline & EAMA@H6 & EAMA@N2 & 30.45 & 2.75 & 158.87 \\
\hline \multirow[t]{3}{*}{ CYS@OXT } & EAMA@H4 & EAMA@N2 & 27.12 & 3.08 & 136.44 \\
\hline & EAMA@H5 & EAMA@N2 & 27.62 & 3.02 & 139.61 \\
\hline & EAMA@H6 & EAMA@N2 & 19.47 & 3.06 & 137.85 \\
\hline \multirow[t]{3}{*}{ ASP4@OD1* } & EAMA@H4 & EAMA@N2 & 23.96 & 2.75 & 163.20 \\
\hline & EAMA@H5 & EAMA@N2 & 8.82 & 2.74 & 162.16 \\
\hline & EAMA@H6 & EAMA@N2 & 22.96 & 2.73 & 164.21 \\
\hline \multirow[t]{3}{*}{ ASP4@OD2* } & EAMA@H4 & EAMA@N2 & 10.32 & 2.73 & 164.43 \\
\hline & EAMA@H5 & EAMA@N2 & 22.13 & 2.72 & 162.51 \\
\hline & EAMA@H6 & EAMA@N2 & 11.98 & 2.72 & 164.04 \\
\hline
\end{tabular}

${ }^{*} \mathrm{O}$ and OXT represent the carboxyl oxygen of the -COO- groups of D4 and C5. ${ }^{8} \mathrm{~N} 1$ and N2 represent the nitrogen of the $-\mathrm{NH}$ and $-\mathrm{NH}_{3}$ groups of EAMA, respectively. Hydrogen bonds were determined via the distance between the heavy atoms using a cutoff of $3.5 \AA$ and the angle between the acceptor and donor atoms using a cutoff of $120^{\circ}$. 


\section{REFERENCES}

1 Poma, A.; Guerreiro, A.; Whitcombe, M. J.; Piletska, E. V.; Turner, A.P.F.; Piletsky, S.A. SolidPhase Synthesis of Molecularly Imprinted Polymer Nanoparticles with a Reusable Template"Plastic Antibodies". Adv. Funct. Mater. 2013, 23, 2821-2827.

${ }^{2}$ ANTI-FLAG M2 Affinity Gel Catalog Number A2220 Sigma Aldrich (accesed August 8th, 2020).

3 Boysen, R. I. Advances in the Development of Molecularly Imprinted Polymers for the Separation and Analysis of Proteins with Liquid Chromatography. J Sep Sci. 2019, 42,51-71.

${ }^{4}$ Moser A.C.; Hage D.S. Immunoaffinity Chromatography: an Introduction to Applications and Recent Developments. Bioanalysis 2010, 2,769-790.

${ }^{5}$ Case, D. A.; Cheatham, T. E., 3rd; Darden, T.; Gohlke, H.; Luo, R.; Merz, K. M., Jr.; Onufriev, A.; Simmerling, C.; Wang, B.; Woods, R. J. The Amber Biomolecular Simulation Programs. J. Comput. Chem. 2005, 26,1668-1688.

${ }^{6}$ Schrödinger Release 2018-3: Maestro, Schrödinger, LLC, New York, NY, 2018; Induced Fit Docking protocol; Glide, Schrödinger, LLC, New York, NY, 2018; Prime, Schrödinger, LLC, New York, NY, 2018.

7 VIDA 4.3.0.4: OpenEye Scientific Software, Santa Fe, NM. http://www.eyesopen.com.

8 Wang, J. M.; Wang, W.; Kollman, P. A., Antechamber: An Accessory Software Package for Molecular Mechanical Calculations. Abstr. Pap. Am. Chem. S. 2001, 222,U403.

9 Humphrey, W.; Dalke, A.; Schulten, K., VMD: Visual Molecular Dynamics. J. Mol. Graph. 1996, 14,33-38.

10 The PyMOL Molecular Graphics System, Version 1.8.2.3 Schrödinger, LLC.

${ }^{11}$ Maier, J. A.; Martinez, C.; Kasavajhala, K.; Wickstrom, L.; Hauser, K. E.; Simmerling, C., ff14SB: Improving the Accuracy of Protein Side Chain and Backbone Parameters from ff99SB. J. Chem. Theory Comput. 2015, 11,3696-3713.

12 Jorgensen, W. L.; Chandrasekhar, J.; Madura, J. D.; Impey, R. W.; Klein, M. L., Comparison of Simple Potential Functions for Simulating Liquid Water. J. Chem. Phys. 1983, 79,926-935.

13 Amber parameter database. Maintained by Richard Bryce. http://research.bmh.manchester.ac.uk/bryce/amber. Accessed July 2, 2019.

${ }^{14}$ Fox, T.; Kollman. P.A. Application of the RESP Methodology in the Parametrization of Organic Solvents. J. Phys. Chem. B 1998, 102, 8070-8079.

15 Pastor, R.; Brooks, B.; Szabo, A. An Analysis of the Accuracy of Langevin and Molecular Dynamics Algorithms. Mol. Phys. 1988, 65,1409-1419.

${ }^{16}$ Berendsen, H.J.C.; Postma, J.P.M.; van Gunsteren, W.F.; DiNola, A.; Haak, J.R. Molecular Dynamics with Coupling to an External Bath. J. Chem. Phys. 1984, 81,3684-3690.

${ }^{17}$ Ryckaert, J.P.; Ciccotti, G.; Berendsen, H.J.C., Numerical-Integration of Cartesian Equations of Motion of a System with Constraints - Molecular-Dynamics of N-Alkanes. J. Comput. Phys. 1977, 23, 327-341.

${ }^{18}$ Case, D.; Babin, V.; Berryman, J.; Betz, R.; Cai, Q.; Cerutti, D.; Cheatham, T., III; Darden, T.; Duke, R.; Gohlke, H.; et al. Amber 14; University of California: San Francisco, 2014. 
19 Mezei, M. Simulaid: a Simulation Facilitator and Analysis Program. J. Comput. Chem. 2010, 31,2658-2668.

20 García, N.; Benito, E.; Guzmán, J.; Tiemblo, P. Use of $p$-Toluenesulfonic Acid for the Controlled Grafting of Alkoxysilanes onto Silanol Containing Surfaces: Preparation of Tunable Hydrophilic, Hydrophobic, and Super-Hydrophobic Silica. J. Am. Chem. Soc. 2007, 129, 5052-5060.

${ }^{21}$ Gómez-Arribas, L. N.; Urraca-Ruiz, J. L.; Benito-Peña, E.; Moreno-Bondi, M. C. Tag-Specific Affinity Purification of Recombinant Proteins by Using Molecularly Imprinted Polymers. Anal. Chem. 2019, 91, 4100-4106. 